\title{
CLINICAL APPLICATION OF DRIED BLOOD SPOT FOR MONITORING STUDIES OF TAMOXIFEN, ENDOXIFEN, AND 4-HYDROXYTAMOXIFEN IN BREAST CANCER PATIENT USING LIQUID CHROMATOGRAPHY-TANDEM MASS SPECTROMETRY
}

\author{
YAHDIANA HARAHAP ${ }^{*}$, BAITHA PALANGGATAN MANGGADANI ${ }^{1}$, TESANIKA RIBKA JOULIN SITORUS ${ }^{1}$, \\ CALLISTA ANDINIE MULYADI ${ }^{1}$, DENNI JOKO PURWANTO²
}

\author{
${ }^{1}$ Faculty of Pharmacy, Universitas Indonesia, Depok, Indonesia, ${ }^{2}$ Functional Medical Staff of Surgical Oncology, Dharmais Cancer Hospital, \\ Jakarta, Indonesia
}

Email: yahdiana03@yahoo.com

Received: 15 Oct 2018, Revised and Accepted: 09 Jan 2019

\begin{abstract}
Objective: To determine tamoxifen (TAM) and its metabolites, endoxifen (END) and 4-hydroxytamoxifen (4-HT) in patients' DBS simultaneously for monitoring studies purposes.

Methods: The UPLC-MS/MS method was developed and validated with clomiphene as the internal standard. Optimization was done by evaluating several parameters that affect the efficiency of DBS preparation and analysis of TAM and its metabolites.

Results: Sample preparation was performed by protein precipitation using methanol. The separation was performed on UPLC Class BEH C18 using formic acid $0.1 \%$-formic acid $0.1 \%$ in acetonitrile (35:65) as the mobile phase in isocratic mode at $0.25 \mathrm{ml} / \mathrm{minute}$. The mass detection was performed on Waters Xevo TQD using ESI+for TAM, END, 4-HT, and clomiphene as internal standard with m/z value: 372.2>72.27; 374.29>58.2; 388.29>72.19; dan 406.28>100.17 respectively. This method was linear within the range of 5-200 ng/ml for TAM; $1-40 \mathrm{ng} / \mathrm{ml}$ for END; and 0.5-20 $\mathrm{ng} / \mathrm{ml}$ for 4 -HT with $\mathrm{r}$ value of $\geq 0.9983$; $\geq 0.9964$; and $\geq 0.9981$. \%diff and $\% \mathrm{CV}$ of the assay were within $15 \%$ and within $20 \%$ for LLOQ. The method was applied to 29 breast cancer patients, where the results lied between 30.29 and $188.63 \mathrm{ng} / \mathrm{ml}$ for tamoxifen, 1.45 and $28.77 \mathrm{ng} / \mathrm{ml}$ for endoxifen, 0.21 and $11.28 \mathrm{ng} / \mathrm{ml}$ for 4-hydroxytamoxifen.
\end{abstract}

Conclusion: This method has successfully fulfilled validation requirement referring to 2011 EMA and 2013 FDA guidelines. The method was successfully applied to determine TAM, END, and 4-HT in DBS of breast cancer ER+patients. TAM and its metabolites level in patients were showed high variability with END concentration of 2 patients below the clinical threshold.

Keywords: Tamoxifen, Endoxifen, 4-Hydroxytamoxifen, Clomiphene, Dried blood spot, LC-MS/MS

(C) 2019 The Authors. Published by Innovare Academic Sciences Pvt Ltd. This is an open access article under the CC BY license (http://creativecommons.org/licenses/by/4.0/) DOI: http://dx.doi.org/10.22159/ijap.2019v11i2.30310

\section{INTRODUCTION}

Breast cancer is one of the cancer types with a high percentage of mortality in Indonesia [1]. Most of the cases are caused by estrogen receptor (ER)-positive cancer, so anticancer from selective estrogen receptor modulators (SERMs) are usually used as the first line of the adjuvant therapy [2]. Tamoxifen (TAM) is an anticancer of SERMs and it is a prodrug that will be metabolized by CYP2D6 into active metabolites that have higher affinity to ER than TAM itself [3-5]. TAM is metabolized by CYP2D6 enzyme into endoxifen (END) and 4-hydroxytamoxifen (4HT), both of which are metabolites with antiestrogenic activity 30 to 100fold more potent than TAM itself [5]. Cytochrome 2D6 (CYP2D6) enzyme is polymorphic, so it might result in different metabolic activities for each patient [3-5]. TAM analysis have been done mostly using plasma samples, but plasma sampling of breast cancer patients by venipuncture is considered invasive and painful to patient [3]. Therefore, it is necessary to develop a method for analyzing TAM using sampling that considers patient comfort, namely dried blood spot (DBS), in which this method is more simple, requires less blood volume, and the analyte is more stable [5-7]. However, the levels of analytes in DBS are lower, so a more sensitive and selective method of analysis is needed for TAM, END, and 4-HT [8].

The previous study showed that the efficacy of TAM therapy depended on END threshold concentration. Patient who has END concentration above $5.9 \mathrm{ng} / \mathrm{ml}$ has less recurrence compared to patients with END level below the threshold concentration [4]. This concentration is extrapolated to DBS, resulted in threshold concentration of $3.3 \mathrm{ng} / \mathrm{ml}$ in DBS [3].

In the present study, the monitoring of TAM, END, and 4-HT through quantification in DBS breast cancer patients was developed and applied to determine the levels of TAM metabolites in the blood of breast cancer patients in Indonesia. This method can be used to evaluate the effectiveness of TAM therapy in breast cancer patients and can be considered by doctors for follow-up therapy.

\section{MATERIALS AND METHODS}

Reference standard samples and materials

TAM was purchased from Sigma-Aldrich (Singapore). N-desmethyl-4-HT (ENDE/Z mixture) and 4-HT were purchased from Santa Cruz Biotechnology (USA). Clomiphene was purchased from Fabrica Italiana Sintetici (Italy). Formic acid, acetonitrile HPLC grade, and methanol for analysis were obtained from Merck (Darmstadt, Germany). Perkin Elmer 226 paper was obtained from Perkin Elmer (USA).

\section{Preparation of solutions and standards}

TAM, END, and 4-HT stock solutions were prepared in methanol to obtain a concentration of $1,000 \mathrm{ng} / \mathrm{ml}$ [5]. The stock solution was diluted to obtain intermediate solutions at $100 \mathrm{ng} / \mathrm{ml}$. Working solutions were prepared by dilution of the intermediate solution with methanol. Calibration samples were prepared in whole blood diluting working solutions at 1:20 with whole blood free from the analytes. Clomiphene stock solution was prepared in methanol at $1.000 \mathrm{ng} / \mathrm{ml}$ concentration. Intermediate clomiphene solutions were prepared by dilution of the stock with methanol to obtain a concentration of $100 \mathrm{ng} / \mathrm{ml}$.

\section{Sample preparation}

DBS samples were prepared from freshly drawn whole blood which spotted on the DBS paper and dried for $2 \mathrm{~h}$. The method was referred to [5] with some modification. The blood spots were cut through the spot's diameter. For the extraction of the analytes from the DBS, a $100 \mu \mathrm{l}$ methanol containing $0.1 \%$ clomiphene and 1.000 $\mu \mathrm{l}$ methanol as an extraction solvent were added to the DBS. Then 
the tube was vortexed for 1 minute and sonicated for $25 \mathrm{~min} .850 \mu \mathrm{l}$ of the sample mixture was dried under a gentle stream of nitrogen $\left(55^{\circ} \mathrm{C}\right)$ for 15 minute and the dried extract was dissolved in $100 \mu \mathrm{l}$ $0.1 \%$ formic acid $-0.1 \%$ formic acid in acetonitrile $(35,65)$. The sample mixture was centrifuged for $10 \mathrm{~min}$ at 3,000 rpm, then $60 \mu \mathrm{l}$ of the supernatant was transferred to an auto sampler vial and $10 \mu \mathrm{l}$ was injected onto the LC-MS/MS system.

\section{Liquid chromatography tandem mass spectrometry (LC-MS/MS)}

An LC-MS/MS method was previously used for quantification of TAM and END in DBS and also 4-HT in plasma [3]. Positive electrospray ionization was applied and the transition from precursor into product was set at $\mathrm{m} / \mathrm{z} 372.2>72.22$ for TAM; $374.29>58.2$ for END; $388.29>72.19$ for $4-H T$; and $406.28>100.17$ for clomiphene.

\section{Validation assay}

Validation assay was performed based on Food and Drug Administration (2013) and European Medicines Agency (2011) guidelines for validation of bioanalysis $[9,10]$.

\section{Linearity}

Aliquots of $950 \mu \mathrm{l}$ blank blood were spiked with $50 \mu \mathrm{l}$ stock solutions to obtain eight calibration levels of samples containing TAM $(5,10,25,50,75,100,150$ and $200 \mathrm{ng} / \mathrm{ml})$, END $(1,2,5,10,15$, $20,30$ and $40 \mathrm{ng} / \mathrm{ml})$, and $4-\mathrm{HT}(0,5 ; 1 ; 2 ; 5 ; 7,5 ; 10 ; 15$ and 20 $\mathrm{ng} / \mathrm{ml}$ ). Blank, zero, and calibration samples were applied to Perkin Elmer 226 paper $(3 \times 20 \mu \mathrm{l})$, dried at room temperature for $2 \mathrm{~h}$ and analyzed within $24 \mathrm{~h}$. Replicates at each concentration were analyzed as described above. Calibration curves were calculated relating the area ratios from TAM, END, and 4-HT peaks to the clomiphene peak and with the nominal concentrations of the calibration samples.

\section{Lower limit of quantification (LLOQ)}

An independent DBS quality control sample at the lowest point of the calibration curve at concentrations of $5.0 ; 1.0$; and $0.5 \mathrm{ng} / \mathrm{ml}$ for TAM, END, and 4-HT, respectively was included in the accuracy and precision experiments. This assay was performed with five replicates. The acceptance criteria established for the LLOQ is maximum $20 \%$ for the $\%$ coefficient variation (CV) value.

\section{Accuracy and precision}

Aliquots of blank blood were spiked with standard solutions to obtain 4 types of concentration: LLOQ, Quality control sampel in low, medium, high concentration (QCL, QCM, and QCH) containing TAM, END, and 4-HT. Samples were extracted with the extraction method as described above. This assay was divided into 2 types: within run and between run. Both assays were performed with five replicates. The acceptance criteria established for the accuracy and precision is maximum $20 \%$ for the $\% \mathrm{CV}$ value of LLOQ concentration and $15 \%$ for the \%CV value of QCL, QCM, and QCH concentrations.

\section{Recovery}

Aliquots of blank blood were spiked with standard solutions into obtain QCL, QCM, and QCH concentrations, then samples were extracted and injected to the LC-MS/MS system. Standards containing TAM, END, and 4-HT on QCL, QCM, and QCH concentrations were also injected to the LC-MS/MS system. Both assays were performed with three replicates for each concentration. The acceptance criteria is established for maximum $15 \%$ for the $\mathrm{CV}$ value.

\section{Matrix effect}

Standard solutions of TAM, END, and 4-HT were diluted in the solvent to obtain QCL and QCH concentrations, then injected into the LC-MS/MS system. Furthermore, whole blood from six different sources was extracted with the extraction method as described above, then the analytes were inserted to the samples after the extraction process to obtain QCL and QCH concentrations. The assay was performed with two replicates for each concentration. Matrix effect is showed by calculating the matrix factor. The acceptance criteria established for the matrix effect is maximum $15 \%$ for the $\% \mathrm{CV}$ value in the calculation of standardized normalized matrix factor.

\section{Application of the method}

A total of 29 breast cancer patients who were taking adjuvant hormonal treatment with TAM $(20 \mathrm{mg} /$ day $)$ were enrolled in the study. They were given a full explanation of the procedures during sampling and signed the informed consent prior to participating in this study. The study inclusion criteria were patient that has been diagnosed with breast cancer (ER+) and confirmed by histopathology report, had received TAM in their therapy regimen ( $20 \mathrm{mg} /$ day) for at least $2 \mathrm{mo}$ and aged $25-55 \mathrm{y}$ old during the blood collection. The exclusion criteria were the patient who declared they were unwilling to participate in the study by not signing the informed consent sheet.

Finger prick blood samples were collected from 29 breast cancer patients of Dharmais Cancer Hospital, Jakarta, Indonesia. Around $200 \mu \mathrm{l}$ blood samples were collected from the fingertips. Blood was drawn by finger prick technique using lancet and the first drop of blood from fingertip was thrown away by rubbing it with alcohol swab. The blood drops were collected in a $0.5 \mathrm{ml} \mathrm{K}$-EDTA micro tube. After that, $20 \mu \mathrm{l}$ blood was immediately transferred to DBS paper using a calibrated micropipette and the paper was allowed to dry for $2 \mathrm{~h}$ at room temperature. After the drying process, the DBS paper was stored in plastic seal bag containing desiccant until the time of analysis.

This research has passed the ethical review from the Health Research Ethics Committee of the Faculty of Medicine, Universitas Indonesia with number 0076/UN2. F1/ETIK/2018 and notification of approval from the Health Research Ethics Committee of Dharmais Cancer Hospital with number 038/KEPK/III/2018.

\section{RESULTS AND DISCUSSION}

\section{Chromatography system and preparation of samples}

The LC-MS/MS system analyzed TAM, END, 4-HT, and clomiphene simultaneously with Multiple Reaction Monitoring (MRM) mass spectrometry mode. The capillary pipe voltage was $3.5 \mathrm{kV}$ with $350{ }^{\circ} \mathrm{C}$ for desolvation temperature and $650 \mathrm{~L} /$ hour for the gas flow rate. The detection condition is shown in table 1.

Table 1: Detection condition using MS/MS detector

\begin{tabular}{lllll}
\hline Compounds & Parent ion (m/z) & Daughter ion (m/z) & Cone (V) & Collision energy (V) \\
\hline TAM & 372.2 & 72.27 & 50 & 27 \\
END & 374.29 & 58.20 & 45 & 30 \\
4-HT & 388.29 & 72.19 & 50 & 27 \\
Clomiphene & 406.28 & 100.17 & 45 & 25 \\
\hline
\end{tabular}

Optimal conditions for the analysis can be obtained by optimizing the analysis and sample preparation method. Optimization of the mobile phase combination, composition, and flow rate was done to obtain a good separation. The mobile phase consisted of formic acid $0.1 \%$ formic acid $0.1 \%$ in acetonitrile (35:65) using an isocratic system with a flow rate of $0.25 \mathrm{ml} / \mathrm{min}$. The analysis was performed in $4 \mathrm{~min}$ and peaks were separated in a short retention time, TAM (1.86 min), END (1.06 min), 4-HT (1.1 min), and clomiphene (1.4 min).

Sample preparation is an important factor in bioanalysis because biological samples contain endogenous materials that can interfere with the analysis of compounds. Appropriate sample preparation is 
necessary to minimize the disturbances in the analyses, so the accuracy of the analysis results can be obtained. Protein preparation was chosen because of its simplicity and efficiency $[11,12]$.

The optimum separation conditions for TAM, END, and 4-HT using the protein precipitation method with $1,000 \mu$ methanol as the extraction solution and sonication was applied for $25 \mathrm{~min}$. The samples were injected $10 \mu \mathrm{l}$ into the LC-MS/MS system using a $0.1 \%$ formic acid- $0.1 \%$ formic acid in acetonitrile $(35: 65)$ phase with 0.25 $\mathrm{ml} / \mathrm{min}$ resulted in retention time for TAM at $1.86 \mathrm{~min}$, END at 1.11 min, 4-HT at $1.15 \mathrm{~min}$, and clomiphene at $1.41 \mathrm{~min}$.

The method proposed in the present study has several advantages over the methods reported in the literature for TAM, such as short analysis time ( 4 min per sample), simple sample preparation, and more convenient for the patient. Moreover, the method was used to measure the concentration of TAM and its metabolites (END and 4-
HT) for a clinical study of breast cancer patients.

\section{Validation assay}

Full validation assay has been conducted in the previous study and in the same laboratory. As shown in table 2, the intra and inter-assay precision and accuracy experiments performed on LLOQ and QC samples (QCL, QCM, and QCH) were fulfilled the requirement of EMA and FDA. Within run and between run imprecisions were in the 3.56 to $8.67 \%$ and 4.2 to $10.82 \%$ ranges, respectively. Accuracy within run and between run was estimated at \% bias-9.47 to $14.88 \%$ and- 19.63 (LLOQ) to $11.4 \%$. LC with MS/MS methods should exclude any matrix effects. The effect of matrix was showed by analysis between the analyte area added after the blank extraction process compared to the area of standard solution in the solvent. As shown in table 2, this method showed acceptable matrix effect ranging from 85.78 to $99.71 \%$ with variability (CV) under $10 \%$.

Table 2: Summary of full validation results

\begin{tabular}{|c|c|c|c|c|c|c|c|c|c|c|}
\hline \multirow[t]{2}{*}{ Analyte } & \multirow[t]{2}{*}{ QC } & \multirow[t]{2}{*}{$\begin{array}{l}\text { Conc. } \\
\text { (ng/ml) }\end{array}$} & \multicolumn{2}{|c|}{ Precision $(\% \mathrm{CV})$} & \multicolumn{2}{|c|}{ Accuracy (\% bias) } & \multicolumn{2}{|c|}{ Matrix effect } & \multicolumn{2}{|c|}{$\begin{array}{l}\text { Internal standard- } \\
\text { normalized matrix factor }\end{array}$} \\
\hline & & & $\begin{array}{l}\text { Within } \\
\text { run }\end{array}$ & $\begin{array}{l}\text { Between } \\
\text { run }\end{array}$ & $\begin{array}{l}\text { Within } \\
\text { run }\end{array}$ & $\begin{array}{l}\text { Between } \\
\text { run }\end{array}$ & $\begin{array}{l}\text { Mean } \\
\% \pm \text { SD) }\end{array}$ & $\% \mathrm{CV}$ & Mean \% $\%$ SD) & $\% \mathrm{CV}$ \\
\hline \multirow[t]{4}{*}{ TAM } & LLOQ & 5.00 & 5.46 & 7.44 & -7.33 & -16.95 & & & & \\
\hline & QCL & 25.00 & 4.71 & 4.20 & -7.85 & -9.90 & $85.78 \pm 2.32$ & 2.71 & $0.89 \pm 0.02$ & 2.41 \\
\hline & QCM & 75.00 & 5.24 & 5.17 & -6.15 & 10.25 & & & & \\
\hline & $\mathrm{QCH}$ & 150.00 & 4.02 & 4.51 & -6.15 & -10.16 & $98.55 \pm 0.46$ & 0.46 & $1.02 \pm 0.01$ & 1.12 \\
\hline \multirow[t]{4}{*}{ END } & LLOQ & 1.00 & 6.27 & 9.32 & 10.09 & -19.63 & & & & \\
\hline & QCL & 5.00 & 8.25 & 5.93 & -9.47 & -12.63 & $93.71 \pm 2.74$ & 2.92 & $0.97 \pm 0.03$ & 3.54 \\
\hline & QCM & 15.00 & 3.56 & 5.40 & -6.35 & -12.29 & & & & \\
\hline & $\mathrm{QCH}$ & 30.00 & 5.20 & 4.11 & -8.60 & -8.60 & $92.93 \pm 8.35$ & 8.98 & $0.96 \pm 0.08$ & 8.82 \\
\hline \multirow[t]{4}{*}{ 4-HT } & LLOQ & 0.50 & 8.67 & 10.82 & 14.88 & -18.11 & & & & \\
\hline & QCL & 2.50 & 5.72 & 4.99 & 11.40 & 11.40 & $87.86 \pm 7.36$ & 8.38 & $0.91 \pm 0.07$ & 7.90 \\
\hline & QCM & 7.50 & 7.66 & 7.17 & 10.25 & -13.42 & & & & \\
\hline & $\mathrm{QCH}$ & 15.00 & 4.65 & 5.21 & -7.01 & -12.22 & $99.61 \pm 7.71$ & 7.74 & $1.03 \pm 0.08$ & 7.94 \\
\hline Clomiphene & & & & & & & $96.91 \pm 0.89$ & 0.92 & & \\
\hline
\end{tabular}

QC: Quality Control, LLOQ: Lower limit of Quantification, QCL: low level, QCM: medium level, QCH: high level, CV: variability, number of experiments (n): 3

Table 3: Summary of partial validation results

\begin{tabular}{|c|c|c|c|c|c|c|c|}
\hline \multirow[t]{2}{*}{ Analyte } & \multirow[t]{2}{*}{ Linear regression } & \multirow[t]{2}{*}{ QC } & \multirow[t]{2}{*}{ Conc. (ng/ml) } & \multirow{2}{*}{$\begin{array}{l}\text { Precision } \\
\% \mathrm{CV} \\
\end{array}$} & \multirow{2}{*}{$\begin{array}{l}\text { Accuracy } \\
\% \text { Bias } \\
\end{array}$} & \multicolumn{2}{|l|}{ Recovery } \\
\hline & & & & & & $\%$ mean \pm SD & $\% \mathrm{CV}$ \\
\hline \multirow[t]{4}{*}{ TAM } & $y=0.0143+0.0115 x$ & LLOQ & 5.00 & 4.90 & -7.70 & & \\
\hline & $r=0.9996$ & QCL & 25.00 & 6.34 & -12.90 & $71.27 \pm 4.34$ & 6.09 \\
\hline & & QCM & 75.00 & 5.42 & -8.25 & & \\
\hline & & $\mathrm{QCH}$ & 150.00 & 5.46 & 7.27 & & \\
\hline \multirow[t]{4}{*}{ END } & $y=0.0003+0.0017 x$ & LLOQ & 1.00 & 4.37 & 18.69 & & \\
\hline & $r=0.9977$ & QCL & 5.00 & 5.47 & -10.88 & $81.15 \pm 4.33$ & 5.34 \\
\hline & & QCM & 15.00 & 2.18 & -13.11 & & \\
\hline & & $\mathrm{QCH}$ & 30.00 & 3.14 & 6.29 & & \\
\hline \multirow[t]{4}{*}{ 4-HT } & $y=0.0029+0.0034 x$ & LLOQ & 0.50 & 14.44 & 17.60 & $81.87 \pm 7.80$ & 9.52 \\
\hline & $\mathrm{r}=0.9958$ & QCL & 2.50 & 10.25 & 11.01 & & \\
\hline & & QCM & 7.50 & 7,36 & -9.50 & & \\
\hline & & $\mathrm{QCH}$ & 15.00 & 5,13 & 6.73 & & \\
\hline Clomiphene & & & & & & $80.79 \pm 1.32$ & 1.63 \\
\hline
\end{tabular}

QC: Quality Control, LLOQ: Lower limit of Quantification, QCL: low level, QCM: medium level, QCH: high level, CV: Coefficient Variation, number of experiments (n): 3

The partial validation was performed in this study as shown in table 3 . The linearity of each calibration curve was determined by plotting the peak area ratio $(y)$ of the analyte to the internal standard versus the nominal concentration (x) of TAM, END, and 4-HT. The calibration curves were linear over the concentration range of $5.0-200.0 \mathrm{ng} / \mathrm{ml}$ for TAM; $1.0-40.0 \mathrm{ng} / \mathrm{ml}$ for END; and $0.5-20.0 \mathrm{ng} / \mathrm{ml}$ for $4-\mathrm{HT}$ with a correlation coefficient of 0.99 for those three compounds.

Accuracy and precision were calculated using within run and between run test at LLOQ, QCL, QCM, and QCH concentration levels. The accuracy (\%bias value) TAM, END, and 4 HT were less than
$20 \%$. The precision (\%CV value) of TAM $4.90-6.34 \% ; 2.18-4.37 \%$ for END; and $5.13-14.44 \%$ for 4-HT. Recovery was calculated using three replicates at three concentration levels: QCL, QCM, and QCH. The mean recovery (\%recovery value) for TAM, END, and 4-HT was $71.27 \pm 4.34 \%$; $81.15 \pm 4.33 \%$; and $81.87 \pm 7.80$ with $\% \mathrm{CV}$ value less than $15 \%$ for all compounds. The results showed that the method is reliable within the analytical range.

This method was applied for the determination of DBS concentration of TAM, END and 4-HT in 29 patients with a daily dose of $20 \mathrm{mg}$ TAM. Sampling was conducted in outpatient subject that 
already reach steady state level of TAM. The results of the analysis on 29 samples showed that all samples contained TAM, END and 4-
HT. Our data showed a wide range of drug DBS concentrations among patients.

Table 4: Result of analysis in breast cancer patients

\begin{tabular}{llll}
\hline Patient & Measured concentration $\mathbf{( n g} / \mathbf{m l})$ & & 4-HT \\
\cline { 2 - 4 } & TAM & END & 5.74 \\
\hline SN 01 & 164.61 & 25.30 & 4.48 \\
SN 02 & 144.44 & 24.10 & 4.86 \\
SN 03 & 114.12 & 28.77 & 7.36 \\
SN 04 & 105.33 & 24.84 & 6.64 \\
SN 05 & 139.95 & 18.42 & 4.32 \\
SN 06 & 104.97 & 6.62 & 0.72 \\
SN 07 & 183.52 & 26.63 & 6.58 \\
SN 08 & 58.27 & 6.72 & 6.08 \\
SN 09 & 98.21 & 16.97 & 6.73 \\
SN 10 & 94.32 & 17.10 & 8.19 \\
SN 11 & 67.15 & 9.29 & 1.00 \\
SN 12 & 140.28 & 10.88 & 2.13 \\
SN 13 & 127.88 & 9.50 & 3.21 \\
SN 14 & 160.31 & 4.55 & 6.46 \\
SN 15 & 178.72 & 19.43 & 11.28 \\
SN 16 & 61.57 & 13.95 & 3.11 \\
SN 17 & 100.97 & 21.56 & 4.59 \\
SN 18 & 154.82 & 9.42 & 3.36 \\
SN 19 & 138.81 & 10.72 & 5.43 \\
SN 20 & 120.02 & 12.79 & 7.26 \\
SN 21 & 188.63 & 18.18 & 2.56 \\
SN 22 & 13.38 & 11.07 & 1.87 \\
SN 23 & 96.03 & 3.75 & 0.96 \\
SN 24 & 39.68 & 5.36 & 0.21 \\
SN 25 & 30.29 & 2.22 & 1.45 \\
SN 26 & 54.46 & 1.45 & 0.44 \\
SN 27 & 39.68 & 5.96 & 1.21 \\
SN 28 & 35.23 & 8.70 & 1.45 \\
SN 29 & 39.20 & 3.98 & \\
\hline
\end{tabular}

The lowest TAM level was found in patient SN 25 of $30.29 \mathrm{ng} / \mathrm{ml}$ and the highest level of TAM which is $188.63 \mathrm{ng} / \mathrm{ml}$ was present inpatient SN 21 . The mean value of TAM levels in DBS was $110.02 \mathrm{ng} / \mathrm{ml}$ with standard deviation of 47.68 and the coefficient of variation of $43.33 \%$.

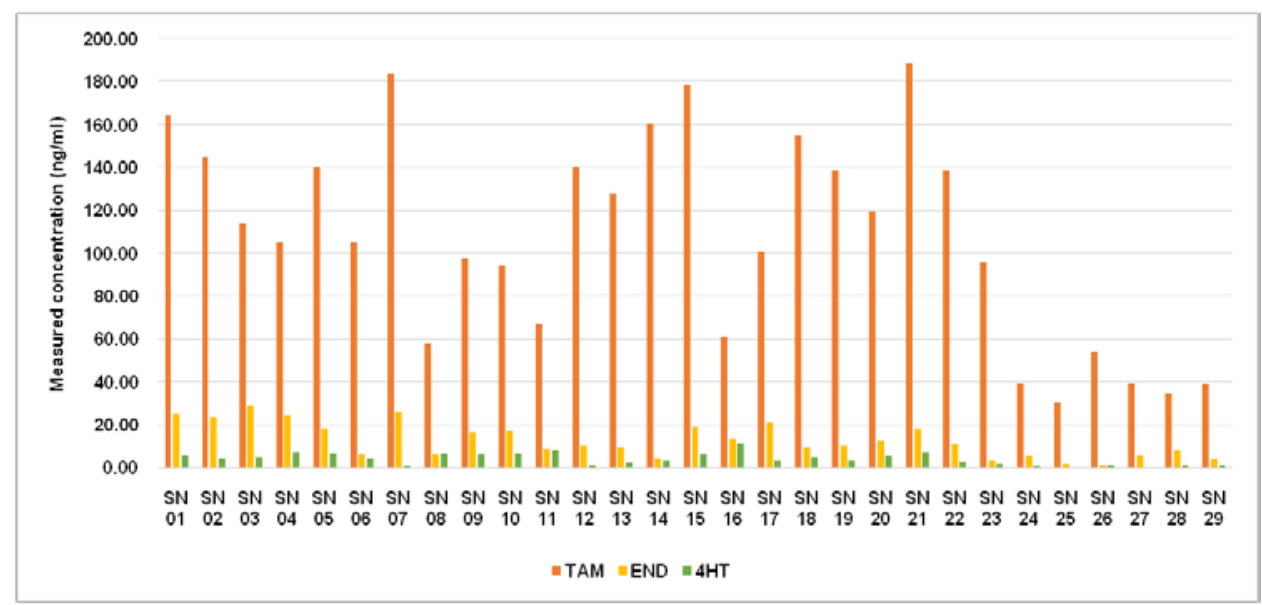

Fig. 1: Graph of TAM, END and 4-HT analysis result in 29 patients (number of experiments (n: 29), n: 29, mean value of TAM: 110.02 $\mathrm{ng} / \mathrm{ml} \pm 43.33 \%$, END: 13.04 ng/ml $\pm 61.48 \%$, 4-HT: $4.13 \mathrm{ng} / \mathrm{ml} \pm 67.75 \%$

This variation between patients was also found in the results of END analysis. The lowest END levels were present in patient SN 26 of $1.45 \mathrm{ng} / \mathrm{ml}$ and the highest levels of $28.77 \mathrm{ng} / \mathrm{ml}$ were present in patient SN 03. END levels in DBS had an average value of 13.04 $\mathrm{ng} / \mathrm{ml}$ with standard deviation of 8.02 and the variation coefficient of $61.48 \%$. The results of 4 -HT analysis also shown variation between patients. The lowest 4-HT level of $0.21 \mathrm{ng} / \mathrm{ml}$ was found in patient SN 25 and the highest level of $11.28 \mathrm{ng} / \mathrm{ml}$ was found in patient SN 16. 4-HT level in DBS had an average value of $4.13 \mathrm{ng} / \mathrm{ml}$ with standard deviation of 2.79 and the variation coefficient of $67.75 \%$. Based on the data obtained, it can be concluded that TAM, END, and 4-HT levels in the DBS between patients vary widely. The graph of TAM, END, 4-HT analysis in breast cancer patients is shown on fig. 1. The analytical result data is shown on table 4 . Concentration range of END and 4-HT found in this study showed high variability. This shows that on the same dosage, different metabolism in every patient lead to different level of metabolites formation, thus affecting TAM efficacy. 
The efficacy of TAM therapy in breast cancer patients is correlated to the END clinical threshold in blood. Based on the previous study, $96 \%$ patient with END serum concentration above $5.9 \mathrm{ng} / \mathrm{ml}$ had a $26 \%$ reduction of recurrences comparing with patients with END concentrations below the threshold [4]. This concentration is extrapolated to DBS, resulted in END threshold concentration of 3.3 $\mathrm{ng} / \mathrm{ml}$ in DBS. Based on the END threshold concentration, 2 patients have END concentration below the clinical threshold. The variation of concentrations may be attributed to the inter-individual pharmacokinetic variability, including polymorphisms of CYP2D6 and CYP3A4 and drugs interaction [5, 13].

\section{CONCLUSION}

The developed method for determination TAM, END, and 4-HT using LC-MS/MS has a simple sample preparation and rapid analysis run time. This method met the 2011 European Medicines Agency (EMA) and 2013 Food and Drug Administration (FDA) bioanalytical guideline for validations. This method was successfully applied to 29 breast cancer patients, including 2 patients with END level below the threshold concentration.

\section{ACKNOWLEDGMENT}

This work was supported by PTUPT Grant (434/UN2. R3.1/HKP05.00/2018) by Ministry of Research, Technology, and Higher Education of Indonesia. The funder had no role in study design, data collection and analysis, decision to publish, or preparation of the manuscript.

\section{AUTHORS CONTRIBUTIONS}

All authors have contributed equally

\section{CONFLICTS OF INTERESTS}

Declared none

\section{REFERENCES}

1. Ministry of Health of the Republic of Indonesia. Riset Kesehatan Dasar; RISKESDAS. Jakarta: Ministry of Health of the Republic of Indonesia; 2013. p. 13.

2. Goodman LS, Brunton LL, Chabner B, Knollmann BC. Goodman and gilman's pharmacological basis of therapeutics. New York: McGraw-Hill; 2012.
3. Jager NGL, Rosing H, Schellens JHM, Beijnen JH, Linn SC. Use of dried blood spots for the determination of serum concentrations of TAM and END. Breast Cancer Res Treat 2014;146:137-44.

4. Madlensky L, Natarajan L, Tchu S, Pu M, Mortimer J, Flatt S, et al. TAM metabolite concentrations, CYP2D6 genotype, and breast cancer outcomes. Clin Pharmacol Ther 2010;89:718-25.

5. Antunes M, Raymundo S, de Oliveira, Staudt D, Gössling G, Peteffi G, et al. Ultra-high performance liquid chromatography tandem mass spectrometric method for the determination of TAM, N-desmethyl TAM, 4-HT and END in dried blood spotsdevelopment, validation and clinical application during breast cancer adjuvant therapy. Talanta 2014;132:775-84.

6. Li W, Tse FLS. Dried blood spot sampling in combination with LC-MS/MS for quantitative analysis of small molecules. Biomed Chromatogr 2010;24:49-65.

7. Tre-Hardy M, Capron A, Antunes M, Linden R, Wallemacq P. Fast method for simultaneous quantification of TAM and metabolites in dried blood spots using an entry level LCMS/MS system. Clin Biochem 2016;49:1295-8.

8. Jager N, Rosing H, Linn S, Schellens J, Beijnen J. Importance of highly selective LC-MS/MS analysis for the accurate quantification of TAM and its metabolites: focus on END and 4HT. Breast Cancer Res Treat 2012;133:793-8.

9. European Medicines Agency. Guideline of Bioanalytical Method Validation. Sciences Medicines Health. London: European Medicines Agency; 2011.

10. Food and Drug Administration. Guidance for Industry, Bioanalytical Method Validation. U. S. Department of Health and Human Services; 2013.

11. Hemavathi G, Hipparagi SM. Sensitive LC-MS/MS method for the simultaneous determination of bisoprolol and triamterene in human plasma. Asian J Pharm Clin Res 2017; 10:341

12. Mukti AA, Jannah F, Nurrochmad A, Lukitaningsih E. Development and validation method for quantitative determination of ciprofloxacin in human plasma and its application in bioequivalence test. Asian J Pharm Clin Res 2016;9:89-95.

13. Saladores P, Mürdter T, Eccles D, Chowbay B, Zgheib NK, Winter $\mathrm{S}$, et al. Tamoxifen metabolism predicts drug concentrations and outcome in premenopausal patients with early breast cancer. Pharmacogenomics J 2015;15:8494. 